\title{
Using customer-focused research and design to build a self-service online store: a case study
}

This article was published in the following Dove Press journal:

Comparative Effectiveness Research

4 February 2013

Number of times this article has been viewed

\section{Michael B Ahmadi' \\ William Trefzger ${ }^{2}$ \\ Rich Morey' \\ lleana Quintas ${ }^{3}$}

'Substance Abuse and Mental Health Services Administration, Rockville, ${ }^{2}$ Centers for Medicare and Medicaid Services, Baltimore, ${ }^{3} \mathrm{Q}$ Solutions, Inc, Rockville, MD, USA
Correspondence: Michael Ahmadi FDA Center for Tobacco Products, 9200 Corporate Boulevard, Room I30N, Rockville, MD 20850, USA

Tel +I 2404024052

Email michael.ahmadi@fda.hhs.gov

Ileana Quintas

IQ Solutions, I I 300 Rockville Pike, Suite 90I, Rockville, MD 20852, USA

$\mathrm{Tel}+\mid 30$ | 984 |47|

Email iquintas@iqsolutions.com
Abstract: American government information centers need to be responsive to an increasingly customer driven information environment while ensuring the sustainability of operations. Enhanced self-service options offer one avenue for addressing both of these needs. This article presents a case study of how the US Substance Abuse and Mental Health Services Administration used extensive stakeholder research and a customer-centric design to reframe its service model by building a self-service online store that integrates access to more than 1300 behavioral health publications previously housed in two separate clearinghouses. The redesigned Substance Abuse and Mental Health Services Administration Store offers users a modern e-commerce website that not only helps customers find, order, download, and share products, but also encourages serendipitous content exploration, which has led to increased orders containing both substance abuse and mental health publications.

Keywords: customer research, taxonomy, usability testing, web analytics, web design

\section{Introduction}

The Substance Abuse and Mental Health Services Administration (SAMHSA) manages one of the largest information dissemination efforts within the US Department of Health and Human Services. The agency historically operated two separate clearinghouses with highly disparate websites to disseminate behavioral health information. The National Clearinghouse for Alcohol and Drug Information (NCADI) was the source for substance abuse information, and the National Mental Health Information Center (NMHIC) provided information on mental health disorders. These information centers were represented not only by separate websites, but also by separate branding and marketing activities, and parallel, yet disconnected, contact center and warehouse operations.

Understanding that mental health and substance use disorders are inextricably linked, ${ }^{1-4}$ SAMHSA decided to merge its free publication offerings on these related topics into one integrated, online SAMHSA Store that would create a seamless digital system with existing inventory and order processing systems, and that would also incorporate successful and familiar features of e-commerce websites. ${ }^{5}$

SAMHSA recognized, like other government agencies that manage information centers, that it needed to be responsive to an increasingly customer-driven information environment while ensuring the sustainability of operations. ${ }^{6-9}$ Consolidating its customer service functions into a single point of access on the web would allow the agency to serve customers better and more efficiently. An online store also would enable 
SAMHSA to respond to federal mandates that call for shifting to primarily digital based information and services to help lower costs. ${ }^{10}$

SAMHSA decided to invest in creating a dissemination platform that would use new web-based technologies to make it easy for professionals and the public to browse, find, use, and share behavioral health content anytime, anywhere, and on any device. ${ }^{11}$ Ultimately, SAMHSA's goal is to get behavioral health information more rapidly into the hands of more professionals, consumers, and other stakeholders who have an interest in supporting SAMHSA's mission to reduce the impact of substance use and mental illness on America's communities.

\section{Methodology}

SAMHSA created an interdisciplinary team and applied a user-centered design process to developing a customerfriendly, self-service publications store. ${ }^{12-14}$ The predesign phase included a major investment in formative research and requirements gathering to obtain a detailed picture of the agency's customers and web environment. The process combined quantitative and qualitative research on SAMHSA's audiences and content, persona development, and content analyses. This research informed the development of a taxonomy and an information architecture that were designed to facilitate customers' self-service experience by managing content in ways that made it searchable and findable.

\section{Customer research}

The SAMHSA team kept its customers at the center of all planning and design by conducting research to discover their needs and information-seeking habits. Surveys and analyses encompassed both quantitative and qualitative research assessing both internal and external SAMHSA customers, including various types of professional and nonprofessional behavioral health constituencies. The data gathered by these efforts sequentially informed subsequent phases of research and the development of customer-centric planning tools. Figure 1 shows the process through which this research informed the development of customer personas and the store website design. Customer research focused initially on a broad spectrum of SAMHSA stakeholders and audiences, and then gradually focused on core audiences as they were identified. The research included the following key components:

- Program review: a program review conducted at the beginning of the consolidation effort used key informant interviews to gather input from 97 participants on how

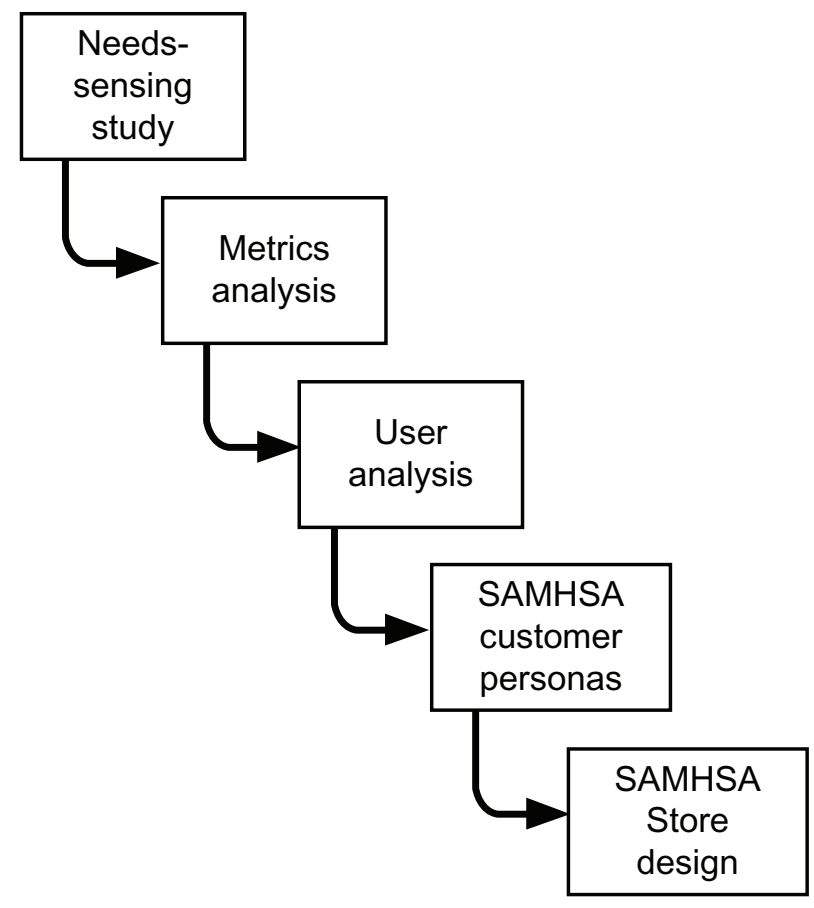

Figure I The process through which research informed the development of customer personas and the store website design.

Abbreviation: SAMHSA, Substance Abuse and Mental Health Services Administration.

the two information centers were regarded by the field, and to identify recommendations for how these centers might be improved.

- Needs sensing study: a follow-up study involved site visits and unstructured interviews to explore the types of content and formats that key stakeholders would like the clearinghouses to offer, as well as better ways to connect SAMHSA customers to the information that was most important to them.

- Metrics analysis: quantitative information from the existing websites and all other available systems helped the team develop a demographic profile of SAMHSA's audiences. Findings showed that SAMHSA's core customers are primarily well-educated professionals who are typically female and middle aged, and who seek mental health and substance abuse information to share with their colleagues or clients. A smaller but still important audience is made up of nonprofessional customers who tend to seek information for themselves or someone they know.

- User analysis: Qualitative research through 12 in-depth telephone interviews built an expanded image of SAMHSA's core professional customers, who needed easy-to-use web-based options to help them find, screen, and order publications. The analysis also identified an 
important subgroup of customers who distributed large quantities of SAMHSA publications to state and local entities, and who needed special web-based ordering features, such as quick online reorders, higher than usual quantity limits, and back-in-stock alerts.

- Customer personas: Prototypical but research-based profiles of SAMHSA's web customers guided the development of user-friendly copy, navigation, and other features to help make customers' online experience fruitful and personal.

\section{Other predesign analyses and reviews}

In addition to customer research, the SAMHSA team conducted additional reviews and analyses to help streamline and organize content so that customers could find current products more easily.

\section{Content and nonproduct analyses}

As a first step in reorganizing information into a logical, navigable website, the team conducted a review of the large collection of content, including publications, multimedia products, and links housed on the existing sites. Another review helped determine the web content that was not related to SAMHSA products that should be kept on the new store site. The content and nonproduct analyses, combined with the identification and removal of obsolete inventory, helped improve the store's search and navigational efficiency by significantly reducing the number of pages on the new site. The inventory "clean up" also reduced the need for storage space in the physical warehouse, further improving efficiency and cutting costs.

\section{Review of use cases and requirements}

Before the actual programming of the store website began, the team conducted further reviews with SAMHSA staff members to understand the requirements more explicitly. Input was solicited on more than 100 use cases that envisioned how customers would want to interact with various store features. Other reviews focused on web design issues such as taxonomy-based navigation, web analytics, and interactions between the store and the other SAMHSA data systems.

\section{Technical design}

Using the detailed picture of SAMHSA's customers gleaned from research and the profiles of SAMHSA's Web users, the team created the information architecture and user interfaces for the SAMHSA Store. The online store was built on a backend knowledge management system that links the store to SAMHSA's consolidated contact center, inventory, and distribution center, as well as to a behavioral health taxonomy. The incorporation of e-commerce retail features based on successful federal and private sector web models conserved resources, while providing better customer self-service. Multiple phases of usability testing guided the design and refinement of the site.

\section{Taxonomy}

The customized taxonomy makes self-service ordering and downloading faster and easier for customers by using a controlled vocabulary for describing and categorizing all SAMHSA publications. ${ }^{15}$ SAMHSA stakeholders participated in testing to validate the usability of the taxonomy for tagging both substance abuse and mental health products.

The taxonomy currently consists of eight intentionally high-level facets that create "buckets" of similar content, each with a comprehensive list of related mental health and substance abuse terms. Five facets - issues, conditions, and disorders; substances; treatment, prevention and recovery; professional and research topics; and locations - describe the content and provide the highest level of navigation. The remaining three facets - audience, population group, and product format - provide contextual filters for content. Users can also sort materials based on their appropriateness for professionals or for the general public.

The store's navigation design leverages the taxonomy structure to improve usability, enable searching across all SAMHSA topic areas, identify and deliver information on defined criteria more quickly, and provide more inclusive search results. The taxonomy also identifies similar products and related web resources, thus encouraging customers to further explore and engage with SAMHSA content.

\section{e-commerce retail features}

The store design incorporated customer-friendly, selfservice features to help SAMHSA customers find and order or download what they need. These features include mega dropdown menus and suggestions about related publications to help customers find the products they want. Expanded product description pages clearly display publication date, stock availability status, and popularity ranking. A simplified shopping cart modeled on e-commerce sites speeds the online ordering of print publications, and prominently displays alerts to customers as to the availability of electronic versions that they can obtain via download. 
The store also introduced the ability to establish personal accounts to streamline the self-service order process for SAMHSA's many return customers. Registered customers can also access their order histories and favorites lists, and receive email notifications when a specific publication is back in stock. A pilot affiliates program automatically allows registered distributors of SAMHSA materials to order publications in quantities that are higher than the usual limits. The SAMHSA Store also enables sharing via Facebook and Twitter.

\section{Usability testing}

Usability testing was central to designing a better user experience for SAMHSA Store customers. Three phases of usability testing - baseline, prototype, and postlaunch involved in-person and remote users whose demographics were similar to those of actual SAMHSA customers. Participants viewed various scenarios (in different orders) that tested their ability to find the requested information through two types of tasks: (1) moving from the homepage to the content, and (2) making first clicks. First-click tasks provided crucial input because users who select the correct first click have a $90 \%$ chance of successfully finding the online information they seek. ${ }^{16}$ Through the three phases of usability testing, results showed a steady increase in the overall user satisfaction score, while revealing specific opportunities for improvement throughout the design process. Findings for each phase of usability testing are summarized below.

\section{Baseline testing}

Conducted 1 year before the launch of the SAMHSA Store, the baseline usability testing examined the experience of 16 in-person and 31 remote users on the original, separate NCADI and NMHIC websites. Overall satisfaction scores for both sites (61 for NCADI and 57 for NMHIC) were lower than the industry benchmark range of the upper $60 \mathrm{~s}$ to $70 \mathrm{~s} .{ }^{17}$ Specific findings informed the development of the prototype for the new SAMHSA Store, including organization of the site by topic using a combined taxonomy, development of left navigation to help users drill down or further refine their topic, and improvements to the display of publications.

\section{Prototype testing}

Prototype testing examined participants' experiences using a clickable HyperText Markup Language prototype of the new SAMHSA Store. The prototype testing, conducted from September to October 2009, involved eight in-person and 17 remote users. Participants explored two prototypes that differed in two main aspects: (1) the layouts for both the publication retrieval lists and left navigation, and (2) the presence or lack of a tab for the location taxonomy facet. Users were also asked to provide qualitative feedback on three different visual designs for the new site. The overall satisfaction rate for the prototype (63\%) showed some improvement over the baseline scores. The success rate for the prototype with a location tab was $88 \%$, compared to $38 \%$ for the prototype without a location tab. Results led to significant changes in the site structure, such as simplification of the dropdown menus used for filtering and sorting, a revised format for the product description pages, as well as the implementation of the most popular visual design.

\section{Postlaunch testing}

After 2 years of research, design, and testing, the SAMHSA Store (http://www.store.samhsa.gov) was launched in September 2010. Postlaunch usability testing of the site was conducted from January 17, 2011 to January 21, 2011, with eight in-person users and 15 remote users. Compared to earlier prototype testing, most first-click and overall performance measures were much improved. For example, in-person users' overall performance scores during postlaunch testing were $63 \%$ for consumer information on marijuana and $86 \%$ for a suicide prevention product, compared to $38 \%$ and $63 \%$, respectively, during prototype testing. During postlaunch testing, remote users achieved first-click success rates of $84 \%$ for information on child abuse and $84 \%$ for a brochure on teens and tobacco, compared to $12 \%$ and $11 \%$, respectively, for prototype testing. Success rates for finding specific content improved as participants worked through successive scenarios, indicating that users were developing an effective mental model for navigating the site. Issues identified through usability testing as well as through customer feedback via channels such as Twitter (Twitter, Inc, San Francisco, CA), Facebook (Facebook, Inc, Menlo Park, CA), and web surveys were addressed in a series of store updates (see the Results section below).

\section{Results}

The SAMHSA team used a quantitative evaluation approach to assess the SAMHSA Store's success in meeting its objectives, and to develop a platform that would support data-driven decision making about future site enhancements. Based on an analysis of web analytics software packages, the team decided to combine two packages: Google Analytics (Google Inc, Mountain View, CA), which enables fast implementation as well as rapid segmenting and testing, as well as Webtrends (Webtrends, Inc, Portland, OR), which facilitates a more flexible and robust configuration to meet sophisticated analytics needs such as pathing analyses. 
A comprehensive site tagging strategy was then designed to meet both current and future analysis needs.

Prior to the SAMHSA Store's launch in September 2010, the team developed a site evaluation plan that identified key performance indicators to measure the site's success in meeting the following objectives:

1. Increase the visibility of SAMHSA and its products.

2. Improve navigation and functionality, specifically customers' ability to find publications, browse by topic, and complete online orders or downloads.

3. Increase the distribution of publications and other products.

4. Improve customer service.

After the SAMHSA Store was in operation for 4 full months (October 2010 through January 2011), the team conducted an in-depth quantitative analysis, which was updated based on 12 months of data (October 2010 through September 2011) for this case study. Part of these analyses focused on a comparison of web metrics for the new SAMHSA Store as well as for the old sites. However, two analytical constraints limited the ability to perform these comparative analyses:

- The old NCADI and NMHIC websites contained more than 10,000 web pages, which were reduced by $84 \%$ to approximately 1700 pages on the SAMHSA Store site. Because of the significant changes to the site architecture and content, only approximate (rather than direct) comparisons of visits and page views were possible.

- Prior to the SAMHSA Store site launch, site metrics were analyzed directly from log files, which included spider and crawler traffic (ie, nonhuman interactions). Since the launch of the store site, web metrics are being analyzed using tagged files, which include only human (noncrawler) traffic. An effort was made to identify as much of the spider/crawler traffic from the old site data as possible to achieve a more accurate comparison with SAMHSA Store data, which excludes this type of traffic.

\section{Web metrics}

Overall, the web metrics analyses indicated that the new SAMHSA Store met each site objective. (see Table 1).

\section{Visits}

Overall, the rate of trended growth in visits to the SAMHSA Store during the 12 months since the launch has been $8.3 \%$ (see Figure 2). This rate is more than double the annual growth rate for US internet traffic, which was 3\% based on extrapolated data from Internet World Stats ${ }^{18}$ averaged over 2005 through 2010. On a trended basis, new site engagement increased significantly throughout the postlaunch year, improving from 6.56 to 7.45 page views per visit.

\section{Backlinks}

Backlinks are links to any page in the store site that are encoded on an external website. Three months before the SAMHSA Store was launched, more than 70,000 total backlinks to the NCADI and NMHIC sites existed on the internet. At the time of the actual launch, 320 backlinks specifically to the new SAMHSA Store existed. By the end of September 2011, 12,649 backlinks to the store site were in place, an increase of more than $3800 \%$. When the 61,000 backlinks being redirected from the old sites to the SAMHSA Store were taken into account, the

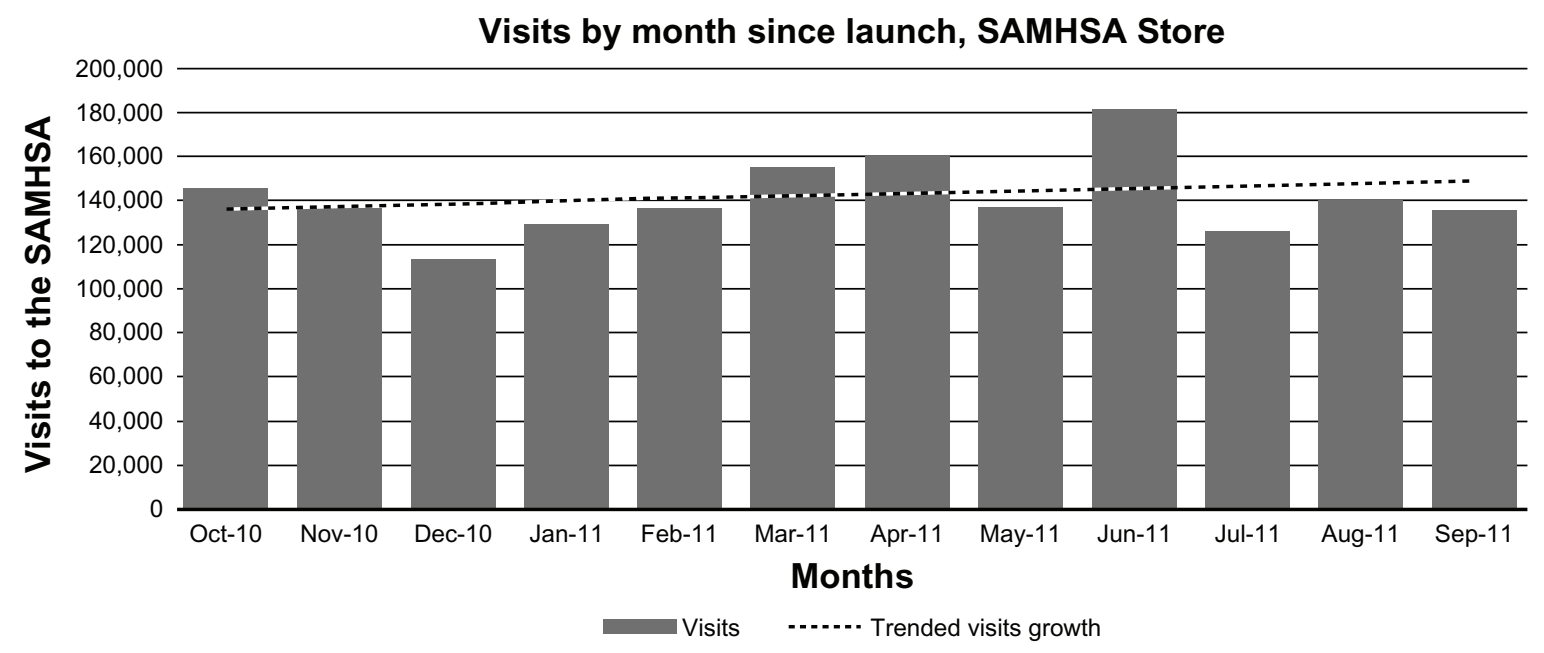

Figure 2 Visits to the SAMHSA Store by month since launch.

Note: Data sourced using Webtrends (Webtrends Inc, Portland, OR, USA) software.

Abbreviation: SAMHSA, Substance Abuse and Mental Health Services Administration. 
store achieved a net gain of 5000 backlinks, or a 5\% increase in the number of backlinks since June 2010 (see Figure 3).

\section{Conversion analysis}

Conversion is a metric that measures the frequency with which users complete an action, such as placing items in a shopping cart and then completing the checkout process. The primary focus for this conversion analysis was to ensure that the SAMHSA Store's checkout process was user friendly, as indicated by a high rate of conversion from opened shopping carts to confirmed orders. The NCADI and NMHIC sites were not tagged; therefore, they did not allow a sophisticated analysis to determine the rate at which shopping carts were abandoned without confirming an order. Consequently, the team elected to measure the SAMHSA Store's performance for this metric against an e-commerce industry benchmark indicating that $40 \%$ of visitors to e-commerce sites who open a shopping cart complete the order process through the sale. ${ }^{19}$ For the SAMHSA Store, we set up a four-step scenario analysis within Webtrends (Webtrends, Inc) to measure conversion from shopping cart initiation to order confirmation. Since the launch of the store site, the shopping cart conversion rate has ranged from $52 \%$ to more than $76 \%$, with an average conversion rate of $63 \%$. This metric exceeds industry benchmarks by more than 50\% (see Figure 4). However, the fact that all SAMHSA products are free might be a contributing factor to the store's comparatively low abandonment rates.

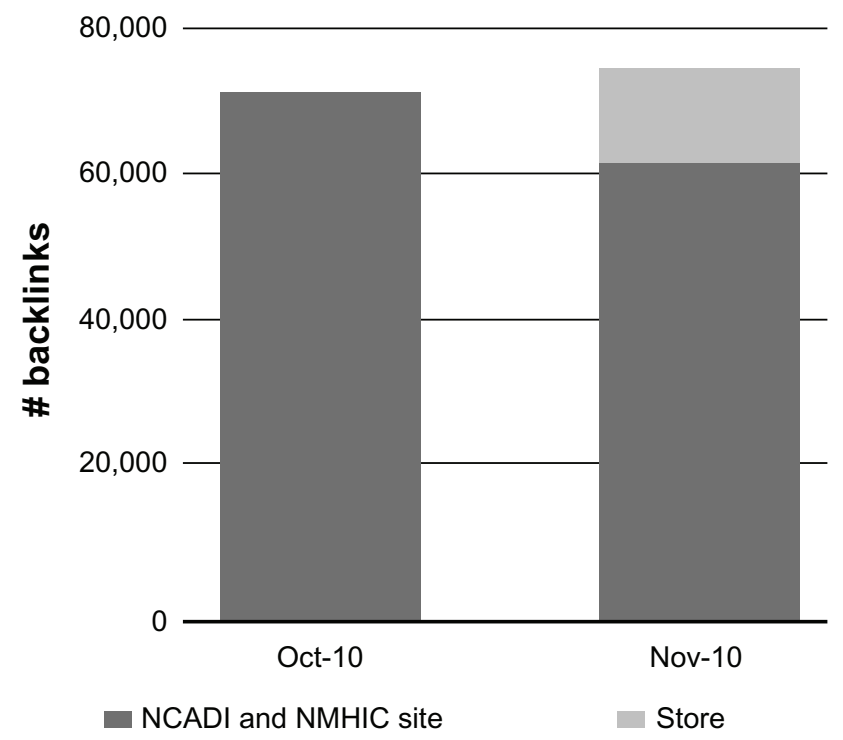

Figure 3 Comparison of NCADI and NMHIC backlinks (June 20I0) to SAMHSA Store backlinks (October 201 I) using Yahoo! Site Explorer.

Abbreviations: NCADI, National Clearinghouse for Alcohol and Drug Information; NMHIC, National Mental Health Information Center; SAMHSA, Substance Abuse and Mental Health Services Administration.

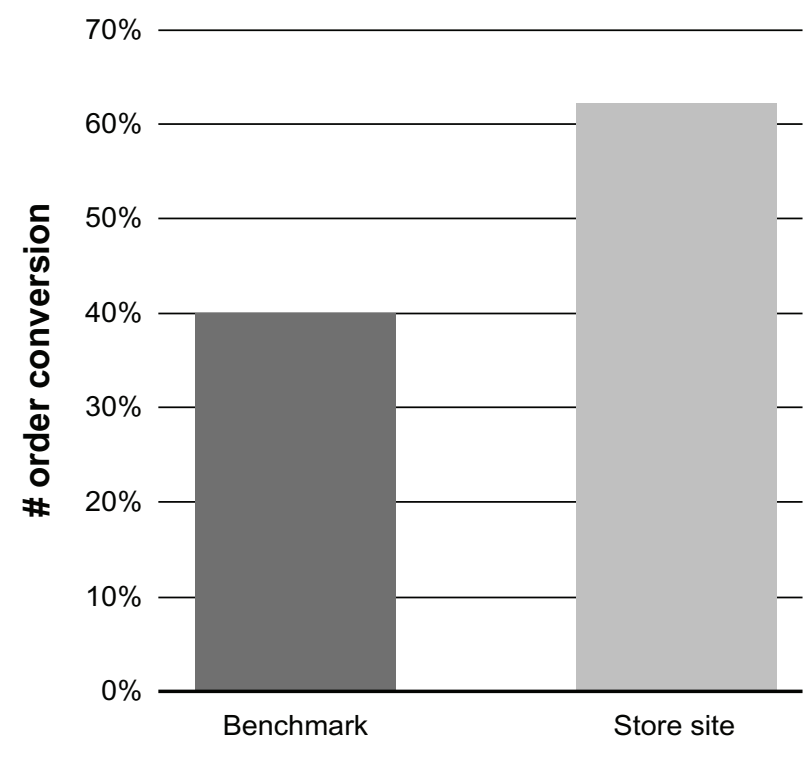

Figure 4 SAMHSA Store order conversion rate, with comparison to an e-commerce benchmark.

Note: Data sourced using Webtrends (Webtrends Inc, Portland, OR, USA) software. Abbreviation: SAMHSA, Substance Abuse and Mental Health Services Administration.

\section{Internal search analysis}

Internal search (IS) rate is a metric used on e-commerce sites to evaluate the effectiveness of the site's design and navigation in helping visitors quickly find products of interest. A relatively low IS rate typically indicates that the site design and navigation are effective, thereby reducing users' reliance on IS. Due to the limitations of the web analytics software used prior to the SAMHSA Store launch, the team was not able to compare IS rates between the NCADI and NMHIC sites and the SAMHSA Store. Instead, the team measured the SAMHSA Store's performance against a 2007 e-commerce site benchmark indicating that $43 \%$ of site visitors to commercial websites use the IS tool to find products of interest. ${ }^{20}$ The SAMHSA Store's IS rate has ranged from 9\% to nearly $15 \%$ over the 12 months since the launch. Because SAMHSA's goal was to make it as easy as possible for site visitors to find products, the team took steps in May 2011 to further reduce the IS rate by featuring publications on the store's homepage and landing pages, and by exposing the site's taxonomy to search engines to bring visitors more directly to their pages of interest. These efforts have helped reduce the store's IS rate to a monthly average of $10.9 \%$ (June through September 2011), compared to the prior monthly average of 13.7\% (October 2010 through May 2011).

\section{Over-limit order channel}

Many of SAMHSA's publications are ordered in large, bulk quantities by local organizations (eg, treatment facilities, or 
Table I KPI measures for the new SAMHSA Store

\begin{tabular}{|c|c|c|c|c|}
\hline \multirow[t]{2}{*}{ KPls } & \multicolumn{4}{|l|}{ Site objectives } \\
\hline & Increase visibility & $\begin{array}{l}\text { Improve navigation } \\
\text { and functionality }\end{array}$ & Increase distribution & $\begin{array}{l}\text { Improve } \\
\text { service }\end{array}$ \\
\hline Visits & $\bullet$ & & & \\
\hline Backlinks & - & & • & \\
\hline Conversion analysis & & $\bullet$ & $\bullet$ & $\bullet$ \\
\hline Internal search analysis & & $\bullet$ & & $\bullet$ \\
\hline Over-limit order channel & & - & - & - \\
\hline PDF downloads & & - & - & - \\
\hline Order analysis & & $\bullet$ & $\bullet$ & $\bullet$ \\
\hline Referral source & - & & - & \\
\hline Visits resulting in orders & & $\bullet$ & $\bullet$ & $\bullet$ \\
\hline and downloads & & & & \\
\hline ForeSee's ACSI results & & - & & - \\
\hline
\end{tabular}

Abbreviations: KPI, key performance indicator; SAMHSA, Substance Abuse and Mental Health Services Administration; PDF, portable document format; ACSI, American Customer Satisfaction Index.

suicide prevention hotlines) that, in turn, distribute the materials in their communities. Before the launch of the online SAMHSA Store, only the SAMHSA contact center could handle requests for bulk quantities that exceeded the order limits established for various publications. To enable more customers to request larger quantities, the SAMHSA Store introduced the ability to handle over-limit orders online seamlessly. After the store launch, the over-limit order volume increased $11 \%$ from 25,000 to nearly 28,000 orders annually, and nearly half of all over-limit requests were handled online (see Table 2). The new functionality was also a driver in increasing the size of online orders (as measured by the number of copies per order) by $55 \%$ (see Table 3 ). The online channel for over-limit orders also collects data that provide SAMHSA with insights about the "true demand" for publications, which can inform decisions about printing levels, as well as the customer's planned dissemination efforts (eg, distribution at conferences).

\section{Order analysis}

A major goal for combining the NCADI and NMHIC websites into the SAMHSA Store was to enable customers to include both mental health and substance abuse publications in a single online order. The results of an order analysis

Table 2 Distribution of request mode for over-limit orders before and after the SAMHSA Store launch

\begin{tabular}{lll}
\hline Request mode & Prelaunch & Postlaunch \\
\hline Contact center & $100.0 \%$ & $51.2 \%$ \\
Web & $0.0 \%$ & $48.8 \%$ \\
Total & $100.0 \%$ & $100.0 \%$ \\
\hline
\end{tabular}

Note: Data sourced using Knowledge Management System created by IQ Solutions (IQ Solutions, Rockville, MD, USA) for SAMHSA.

Abbreviation: SAMHSA, Substance Abuse and Mental Health Services Administration. showed that after the launch of the SAMHSA Store, almost $24 \%$ of orders included both mental health and substance abuse publications, an increase of $156 \%$ (see Figure 5).

\section{Referral source}

Referrals are an exposure measure that indicates how widely the knowledge of a website is distributed. One site objective for the SAMHSA Store focused on increasing exposure to search engines. The store experienced a modest but measurable increase in search engine referrals from $17.0 \%$ of all visits during the first 6 months after launch (October 2010 through March 2011) to 18.1\% during the next 6 months (April 2011 through September 2011). Although no search engine marketing campaigns were conducted, product descriptions and other site elements were optimized for search engines, possibly contributing to the increase in search referrals.

\section{Visits resulting in orders and downloads}

The ratio of orders to web visits has increased significantly on the store site compared to the NCADI and NMHIC sites (see Figure 6). The average number of orders per month being processed through the website increased by more than 600 orders per month (a $7.6 \%$ increase) in the year since the SAMHSA Store launch.

Table 3 Basic order analysis statistics before and after the SAMHSA Store launch

\begin{tabular}{lll}
\hline Period & \% web orders & Copies/order \\
\hline Sep 2009 to Aug 2010 & $77.01 \%$ & 59.2 \\
Oct 2010 to Sep 2011 & $83.35 \%$ & 91.9 \\
\hline
\end{tabular}

Note: Data sourced using Knowledge Management System created by IQ Solutions (IQ Solutions, Rockville, MD, USA) for SAMHSA.

Abbreviation: SAMHSA, Substance Abuse and Mental Health Services Administration. 


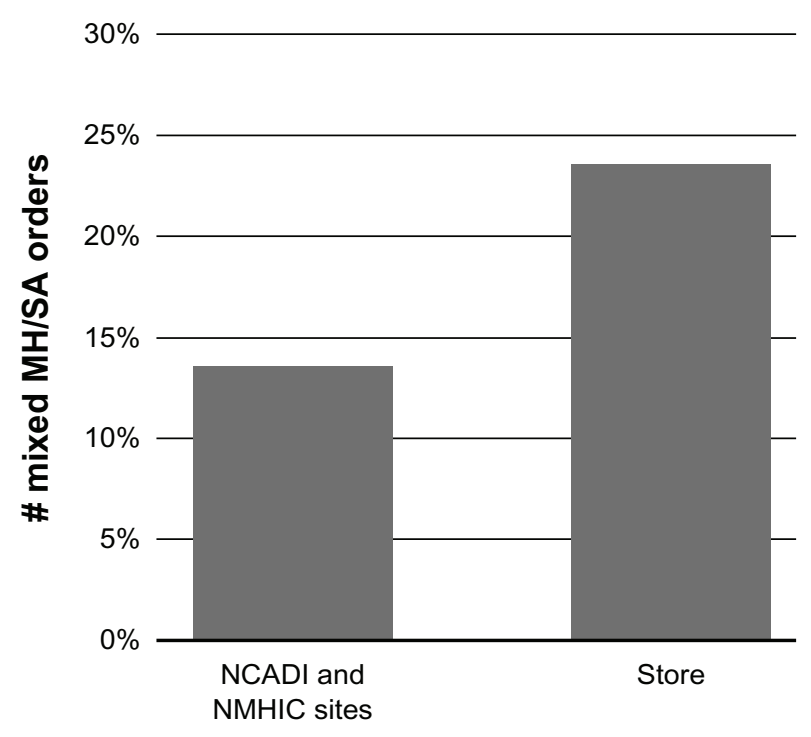

Figure $\mathbf{5}$ The percentage of online orders that included both mental health and substance abuse publications, comparing the NCADI and NMHIC sites and the new SAMHSA Store site.

Abbreviations: NCADI, National Clearinghouse for Alcohol and Drug Information; NMHIC, National Mental Health Information Center; SAMHSA, Substance Abuse and Mental Health Services Administration; $\mathrm{MH}$, mental health; SA, substance abuse.

Downloads are defined as a request for a portable document format (PDF) document on the site. Although the ratio of downloads to visits has decreased on the store site compared to the NCADI and NMHIC sites, it is important to note that substantially fewer PDF documents are available at the new store site than at the old sites. Moreover, the download trend shows a steady increase on the store site, compared to a gradually decreasing trend on the NCADI and NMHIC sites (see Figure 7).

\section{American Customer Satisfaction Index (ACSI)}

SAMHSA measured customer satisfaction based on responses to a set of standard and custom questions in online ACSI surveys. Using the scale of 0 to 100 to grade customer satisfaction, the ACSI score for the NCADI and NMHIC sites had been increasing slowly before the launch of the SAMHSA Store. In the 8 months prior to the store launch, the average ACSI score for the old sites was trending upward from 78 to 79. A "launch effect" has been observed and described for website redesigns, in which the average ACSI score decreases for up to 12 months after a launch, and then slowly increases. The SAMHSA Store experienced this launch effect with an initial ACSI score of 76. However, the store equaled the highest prelaunch score within 6 months and surpassed it by June 2011. The trend toward an improving ACSI score accelerated throughout the postlaunch period, with the SAMHSA Store achieving a customer satisfaction score of 82 in September 2011 (see Figure 8).

\section{Ongoing refinement}

Based on postlaunch testing, web metrics, and other customer feedback, SAMHSA continues to respond to customer feedback by making refinements to the store in monthly postlaunch releases. These ongoing releases further enhance the online browsing and self-service experiences of SAMHSA customers, especially for repeat visitors who frequently order and redistribute agency products. Some of the more noticeable changes to the store include a streamlined homepage and left navigation, easier to find topical and filtering terms, and an automatic advance to the shopping cart after an item has been added. The store helps customers browse other titles within a series of publications, such as the popular "Tips for Teens" and "Technical Improvement Protocols" series, by providing a new navigation option within the top level mega dropdown menus. This option enables users to easily locate series of products and navigate through a particular series with the same ease offered by the taxonomy. The store also automatically surfaces series products that are related specifically to the topic of the

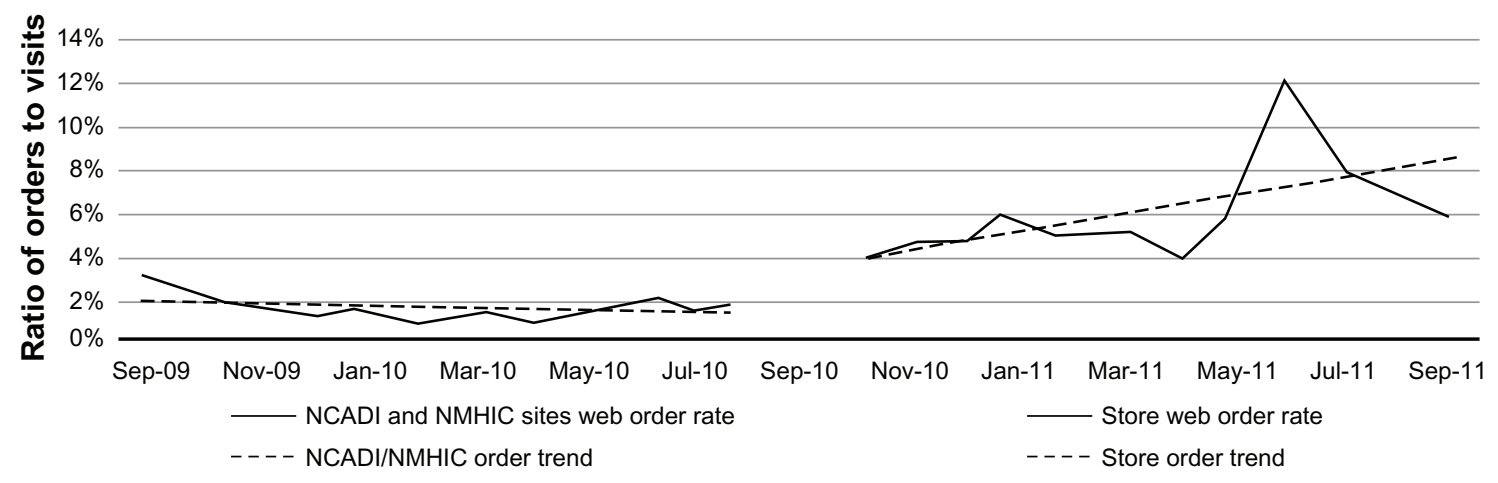

Figure 6 Ratio of orders to visits prelaunch and postlaunch.

Abbreviations: NCADI, National Clearinghouse for Alcohol and Drug Information; NMHIC, National Mental Health Information Center. 


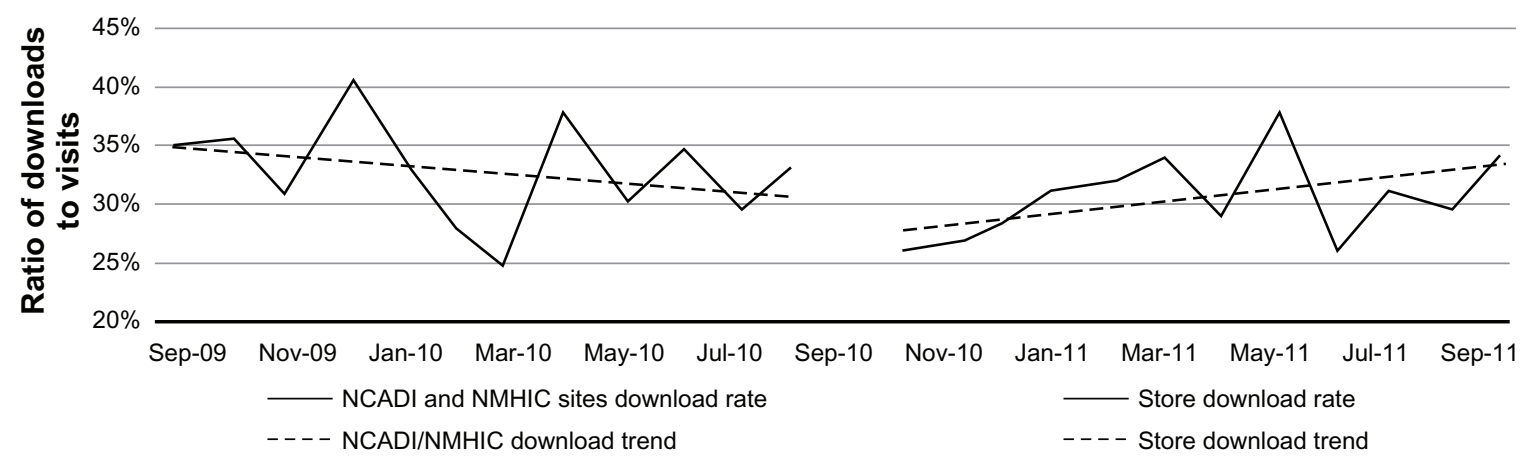

Figure 7 Ratio of downloads to visits prelaunch and postlaunch.

Abbreviations: NCADI, National Clearinghouse for Alcohol and Drug Information; NMHIC, National Mental Health Information Center.

product described. To help nonaffiliated customers complete orders online when they need quantities over the maximum number allowed, the store now prominently displays an overlimit notification that includes a link to an online form for requesting exceptions to the limit. Postlaunch implementation of a persistent cookie now enables the automatic login for registered SAMHSA grantees and affiliates. Since May 2011, the store has seamlessly displayed links to NIH health information on relevant SAMHSA product description pages, thus further expanding self-service access to behavioral health information. The store now enables customers to add a rating and write a comment at a product description page.

\section{Conclusion}

The online store is helping SAMHSA move the dissemination of its large inventory from a primarily print-oriented operation to a model aligned with the modern digital environment and customer-driven marketplaces. The introduction of e-commerce features that address the specific ordering needs of SAMHSA customers has led to improved self-service access to the agency's behavioral health content. Web metrics indicate that store users are becoming more engaged on the site, and that they are finding publications more easily, with less reliance on IS. Conversion rates for order completion are higher than industry standards, and the trends indicate a steady increase in the number of PDF downloads. Equally important for SAMHSA, more orders include both substance abuse and mental health publications, and more customers are making online requests for bulk quantity orders. Such results demonstrate that the store is increasing the visibility of SAMHSA and the dissemination of its products, while improving the online experiences of its customers.

\section{Lessons learned}

SAMHSA's lessons learned during this project's "revisioning" and extensive development phase can be summarized in three elements: "know your audience," the "value of testing," and "patience pays." These three lessons can be of use to other entities, agencies, and organizations engaging in efforts to improve their customer experiences.

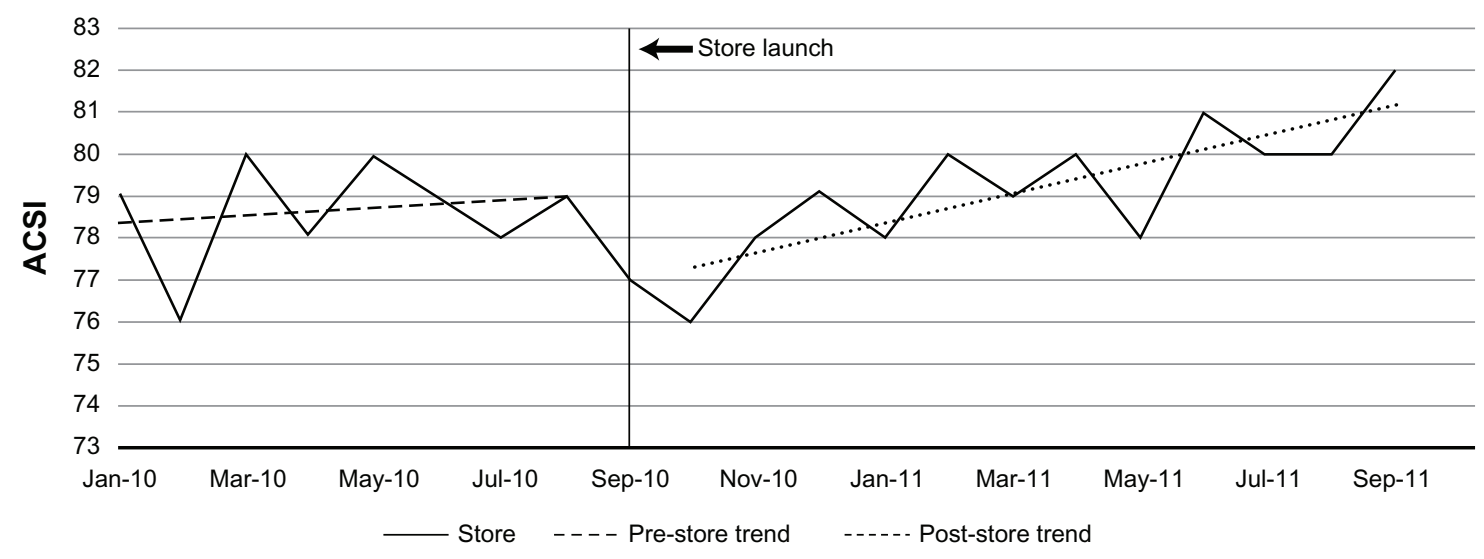

Figure $8 \mathrm{ACSI}$ scores and trends before and after the SAMHSA Store launch.

Abbreviations: ACSI, American Customer Satisfaction Index; SAMHSA, Substance Abuse and Mental Health Services Administration. 


\section{Know your audience}

To create an engaging web resource for customers, it is important to develop a thorough understanding of target audience(s) and their preferences. Beyond a general understanding of an agency's target audience(s), identifying core audiences is of critical importance. When SAMHSA conducted its early analysis and research, the agency found that the majority of users on SAMHSA's existing website were primarily educated, middle-aged women, as well as other health professionals and consumers of substance abuse and mental health information. As a result of this key finding, SAMHSA stepped back from its initial plans to add mobile web services, and focused more on the customer's communication channel preferences. SAMHSA made a strategic decision to take care of its loyal customers first. At the same time, by building flexibility into the system, plans to accommodate future customers with expanded profiles and communication preferences could be included as well. In order to design the store with customers' interests in mind, SAMHSA created "personas" or identities that put a face on the agency's web customers.

\section{Customer personas}

All customer research, particularly the user analysis, informed the development of SAMHSA customer personas. These prototypical, but research-based, profiles of SAMHSA customers were a key tool for informing the user-centric web design. The personas describe the mindsets, needs, and online behaviors of the core types of SAMHSA's web customers: substance abuse service administrators, substance abuse prevention specialists, substance use and mental health service providers, mental health researchers, teachers, consumers, and family members. Personas were also developed for a smaller but important group of customers who order SAMHSA products frequently and in large quantities, often for distribution to a wider audience. These customer types include criminal justice agency staff members, librarians, community leaders, consumer advocates, and SAMHSA staff members. By putting a human face on these users, the personas helped designers imagine how various types of customers would likely interact with SAMHSA Store products and services. In short, the personas guided the development of user-friendly copy, navigation, and other features to help make customers' online experiences productive and personal.

SAMHSA established two sets of personas: one with the existing audience, and another set with the newly identified, future target audiences. The agency recognized that the expansion of its audiences would happen over time, and that adaptation to the website would occur on an ongoing basis to meet changing demands.

\section{The value of testing}

Customer feedback is a lifeline to the relevance of any website. An organization must keep listening to its customers; that work is never done. Usability testing was central to designing a better user experience for SAMHSA Store customers. Three phases of usability testing were conducted - baseline, prototype, and postlaunch - to allow for continuing refinements and enhancements to improve the store's usability as frequently as monthly and no less than quarterly. Customer feedback influenced each one of these refinements to improve service and functionality, whether it was the navigation and placement of specific information on each page, or the taxonomy terms for advanced searches. For example, usability testing illuminated the need for SAMHSA to cross-reference the taxonomy terms for customer searches. Early on, if a customer searched "alcoholism," the results for "alcohol as a substance" were not retrieved. Furthermore, there was no easy way to get those results. To improve search functionality, SAMHSA added a box on the left side of the navigation that featured "related topics." Consequently, when a customer searched "alcoholism," related content also appeared. This example of an enhancement informed by usability testing added tremendous value and resolved an issue that was unidentified during all previous testing.

\section{Patience pays}

The launch of SAMHSA's new store in September 2010 marked the culmination of the clearinghouse consolidation process, creating a single, seamlessly integrated online source of behavioral health information. The development phase to create the store was a long and challenging process, involving many iterations of research, evolutions to the store, and the constant need to balance competing priorities. Driven by a strong desire to provide the customer with everything all at once, the development team realized, at the same time, that this was not a possibility. In order to ensure the store's success, SAMHSA developers had to prioritize features and organize them into phases informed by research, customer needs, and resource requirements. Efforts continued with painstaking thoroughness. With every step calculated to ensure successful completion, SAMHSA learned that doing research on the frontend, for as long as necessary, does lead to better results. If the proper formative research is not conducted, the end result may be more costly, time-consuming revisions. 
These basic themes provided the scaffolding for building an enduring resource that would be adaptable to the many levels of changes yet to be discovered in the world of digital technology.

\section{Implications for the future}

At SAMHSA, the flexibility and scalability of the store lay the foundation for a digital future, where customers will have access to all types of electronic products and resources in any format they desire, and for dissemination on any channel they choose. This approach provides the groundwork for the development of open content that allows SAMHSA to "create once, publish everywhere"21 in a content repository that will house SAMHSA products, and which will be searchable by a keyword taxonomy. At the time the case study was in progress, the innovation of a publications content repository had not been realized. The store created the foundation for the concept of open content for customers.

In May 2012, less than a year after the launch of the SAMHSA Store, the White House released a report. ${ }^{10}$ The report emphasized the importance of focusing on the needs of the customer no matter "whether the customer is in the battle field, the lab, or the classroom."10 SAMHSA's Store and creation of a content repository, currently under development, follow the Digital Government strategy. Harnessing the power of technology will help create a digital, accessible environment in the 21 st century that is "efficient, effective, and focused on improving the delivery of services." 10

At this point, SAMHSA has only scratched the surface of the possibilities associated with making the exchange of vast quantities of public health and behavioral health data and information available to citizens using the device of their choice.

\section{Acknowledgments}

The authors would like to thank the following companies for their support on this project, provided under SAMHSA Contract No 277-04-6091:

- IQ Solutions, Inc, for overall project management; website design, development, and maintenance; metrics analysis; content and nonproduct analyses; use case and requirements reviews; and web metrics analyses;

- Human Interaction Research Institute for the program review, needs sensing study, and customer personas;

- ForeSee Results for the ACSI online surveys;

- Motyka and Company, for the user analysis;

- Taxonomy Strategies, LLC, for taxonomy development and testing;
- Focus on U! and Computer Psychology, Inc, for usability testing.

Lieutenant Commander Michael B Ahmadi is a health services officer in the US Public Health Service. He has led work on transforming SAMHSA's two information clearinghouses into a single customer-driven point of access to behavioral health information. He oversaw the 5-year, phased development of a knowledge management platform that integrates work performed in all areas of information dissemination, as well as the design and implementation of a new online store for SAMHSA products. Lieutenant Commander Ahmadi is currently serving at the US Food and Drug Administration.

Rich Morey has worked in web management for over 6 years. In addition to leading the web and technical portion of the SAMHSA Store project, he also manages the agency's web analytics and web communications programs. Prior to his current role, Rich worked in information technology management at several agencies of the Department of Health and Human Services.

William Trefzger is the Director, Division of website Strategy at the Centers for Medicare and Medicaid Services. He previously served as Lead, Communications Services Team at SAMHSA. He has presented and published on the efforts to improve government and health information services through improved usability and user-centered design.

Ileana Quintas is the founder and CEO of IQ Solutions, a full service communications and health information technology firm providing effective health education programming to improve quality of life for all people. An expert in health communications and management information systems, Ms Quintas leads multidisciplinary teams that create customized solutions for a range of clients, with an emphasis on serving federal government agencies with health mission and research dissemination responsibilities.

\section{Disclosure}

The authors report no conflicts of interest in this work.

\section{References}

1. Substance Abuse and Mental Health Services Administration. Results from the 2009 National Survey on Drug Use and Health: Mental Health Findings. Rockville, MD: Substance Abuse and Mental Health Services Administration, Office of Applied Studies; 2010. Available from http://oas.samhsa.gov/NSDUH/2k9NSDUH/MH/2K9MHResults.pdf. Accessed October 24, 2012.

2. Lemke S, Schaefer JA. VA nursing home residents with substance use disorders: Mental health comorbidities, functioning, and problem behaviors. Aging Ment Health. 2010;14(5):593-602.

3. Centers for Disease Control and Prevention (CDC). Mental health in the United States: health risk behaviors and conditions among persons with depression - new Mexico, 2003. MMWR Morb Mortal Wkly Rep. 2005;54(39):989-991. 
4. Ding K, Yang J, Cheng G, Schiltz T, Summers KM, Skinstad AH. Hospitalizations and hospital charges for co-occurring substance use and mental disorders. J Subst Abuse Treat. 2011;40(4):366-375.

5. Lee S, Koubek RJ. The effects of usability and web design attributes on user preference for e-commerce web sites. Computers in Industry. 2010;61(4):329-341.

6. Downing TA. An initial survey and description of how selected United States government libraries, information centers, and information services provide public access to information via the internet. Proceedings of the Bicentennial Conference on Bibliographic Control for the New Millennium: Confronting the Challenges of Networked Resources and the Web; November 15-17, 2000; Washington, DC. Available from: http://www.eric.ed.gov/ERICWebPortal/search/ detailmini.jsp?_nfpb=true\&_\&ERICExtSearch_SearchValue_0=ED4 54870\&ERICExtSearch_SearchType_0=no\&accno=ED454870.

7. Maguire S, Ojiako U. Market-led systems development: when customers become users. Industrial Management and Data Systems. 2008;108(2): 173-190.

8. Janssen M, Kuk G, Wagenaar RW. A survey of web-based business models for e-government in the Netherlands. Gov Inf Q. 2008;25(2):202-220.

9. Dawes SS, Pardo TA, DiCaterino A. Crossing the threshold: practical foundations for government services on the world wide web. JAm Soc Inf Sci. 1999;50(4):346-353.

10. Executive Office of the President of the United States. Digital Government: Building Blocks of a 21 st Century Platform to Better Serve the American People. Washington, DC: The White House, President Barack Obama; 2012. Available from: http://www.whitehouse.gov/sites/ default/files/omb/egov/digital-government/digital-government-strategy. pdf. Accessed October 24, 2012.

11. Garrett JJ. The Elements of User Experience: User-Centered Design for the Web and Beyond. 2nd ed. Berkley, CA: New Riders; 2011.

12. Park JY. Design process excludes users: the co-creation activities between user and designer. Digital Creativity. 2012;23(1):79-92.
13. Abras C, Maloney-Krichmar D, Preece J. User-centered design. In Bainbridge W, editor. Encyclopedia of Human-Computer Interaction. Thousand Oaks, CA: Sage Publications; 2004.

14. Andrews C, Burleson D, Dunks K, et al. A new method in user-centered design: collaborative prototype design process (CPDP). Journal of Technical Writing and Communication. 2012;42(2):123-142.

15. Liang $\mathrm{H}, \mathrm{Xu} \mathrm{Y}, \mathrm{Li} \mathrm{Y}$. Personalized recommender systems integrating tags and item taxonomy. Web Intelligence and Agent Systems. 2012; 10(3):277-289.

16. Bailey RW. FirstClick Usability Testing [webpage on the Internet]. Denver, CO: WebUsability; 2011. Available from: http://webusability. com/firstclick-usability-testing.html. Accessed December 2011.

17. Sauro J. Measuring usability with the System Usability Scale (SUS) [webpage on the Internet]. Denver, CO: Measuring Usability LLC. Available from: http://www.measuringusability.com/sus.php. Accessed December 2011.

18. Argaez E. Internet World Stats: Usage and Population Statistics. Ohio, USA: Internet World Stats: 2011. Available from http:/www.internetworldstats.com. Accessed November 2011.

19. IBM. IBM coremetrics benchmark reports black Friday and cyber Monday 2010 [webpage on the Internet]. Armonk, NY: IBM Corporation; 2011. Available from: http://www.coremetrics.com/ solutions/benchmark-report-black-friday-cyber-monday-2010.php. Accessed December 2011.

20. Marketing Sherpa. Ecommerce Benchmark Guide 2007. Jacksonville Beach, FL: MarketingSherpa, LLC; 2007. Available from: http://www. marketingsherpa.com/exs/Ecom07Summ.pdf. Accessed December 2011 .

21. Jacobson D. COPE: Create once, publish everywhere. ProgrammableWeb.com; 2012 [authored October 13, 2009]. Available from: http:// blog.programmableweb.com/2009/10/13/cope-create-once-publisheverywhere/. Accessed November 21, 2012.
Comparative Effectiveness Research

\section{Publish your work in this journal}

Comparative Effectiveness Research is an international, peer reviewed open access journal focusing on comparative effectiveness of health care including preventative health care strategies, diagnostic strategies, diagnostic technology, medical devices, drugs, medical technology, health systems and organization. The manuscript management system

\section{Dovepress}

is completely online and includes a very quick and fair peer-review system. Visit http://www.dovepress.com/testimonials.php to read real quotes from published authors. 